\title{
DETERMINAÇÃO DAS PROPRIEDADES TECNOLÓGICAS DE CERÂMICA VERMELHA QUEIMADA À 850C PARA PRODUÇÃO DE BLOCOS DE VEDAÇÃO*
}

\author{
Leda de Azevedo Racanelli ${ }^{1}$ \\ José Antônio da Silva Souza ${ }^{2}$ \\ Alisson Clay Rios da Silva ${ }^{3}$ \\ Sérgio Neves Monteiro \\ Verônica Scarpini Candido ${ }^{5}$
}

\begin{abstract}
Resumo
O estudo da composição mássica de cerâmicas vermelhas é de extrema importância para a produção de peças com propriedades tecnológicas aceitáveis. Nesse contexto esse trabalho tem por objetivo determinar as propriedades tecnológicas de cerâmica vermelha para fabricação de blocos de vedação. Dois tipos de argila foram usados, argila forte e fraca, para a confecção dos corpos de prova que foram moldados por prensagem uniaxial. Após essa etapa foram determinadas a absorção de água e a resistência em flexão. Os resultados mostraram que a massa composta por $50 \%$ de argila forte e $50 \%$ de argila fraca apresentaram os melhores resultados de resistência à flexão. Assim, o estudo mostrou que todas as massas estudadas atendem aos requisitos mínimos exigidos por norma e que a massa composta pela mistura das argilas apresentou o melhor desempenho mecânico tecnológico.
\end{abstract}

Palavras-chave: Argila, Bloco de vedação, Propriedades tecnológicas, Temperatura.

\section{DETERMINATION OF TECHNOLOGICAL PROPERTIES OF RED CERAMICS FIRED AT 850ㄷ FOR THE PRODUCTION OF BRICKS.}

\section{Abstract}

The aim of the work is to determine the technological properties of red ceramics for the manufacture of bricks. Two types of clay were used, strong and weak clay, for the preparation of specimens that were molded by uniaxial pressing. After this step water absorption and flexural strength were determined. The results showed that the mass composed of $50 \%$ of strong clay and $50 \%$ of weak clay presented the best results of resistance to flexion. Thus, the studies showed that all the masses studied meet the minimum requirements required by standard and that the mass composed by the mixture of clays presented the best technological mechanical performance.

Keywords: Brick, Clay, Technological Properties, Temperature.

1 Engenheira de Produção, Mestranda em Engenharia de Processos, Programa de Pós-graduação em engenharia de Processos, Universidade federal do Pará (UFPA), Belém, Pará, Brasil.

2 Engenheiro químico, Doutor em Engenharia de Recursos Naturais, Professor associado II, Faculdade de Engenharia Química, Universidade Federal do Pará (UFPA), Belém, Pará, Brasil.

3 Químico industrial, Doutor em Ciência dos Materiais, Professor Adjunto I, Faculdade de Engenharia de Materiais, Universidade Federal do Pará (UFPA), Ananindeua-PA, Brasil.

4 Engenheiro de Materiais, PhD em Engenharia e Ciência dos Materiais, Professor, Programa de Pós-graduação em Engenharia de Materiais/Departamento de Engenharia mecânica e Materiais, Instituto Militar de Engenharia (IME), Rio de Janeiro, Rio de Janeiro, Brasil.

5 Bióloga, Doutora em Ciência dos Materiais, Professora Adjunta I, Faculdade de Engenharia de Materiais, Universidade Federal do Pará (UFPA), Ananindeua-PA, Brasil.. 


\section{INTRODUÇÃO}

O setor ceramista de São Miguel do Guamá - PA representa um importante polo produtivo e gerador de riquezas para a economia local. Esse setor passou por um processo de modernização ao longo dos anos e tornou-se uma indústria altamente competitiva. Estima-se que atualmente existam cerca de 42 empresas de cerâmicas vermelhas localizadas no município e arredores, sendo que 34 fazem parte do Sindicato e, juntas, conseguem gerar cerca de 3 mil empregos diretos [1].

As argilas utilizadas na região são tipicamente cauliníticas, com baixos teores de óxidos fundentes e baixos percentuais de óxidos de ferro [2]. Por serem argilas pobres em $\mathrm{K} 2 \mathrm{O}$ e $\mathrm{MgO}$, a temperatura de queima utilizada pelas cerâmicas para fabricação de blocos de vedação é relativamente alta, em média, 850 ou $950^{\circ} \mathrm{C}$.

Geralmente, nessas indústrias, não há um controle de qualidade da matériaprima nem das peças isso acarreta em uma grande perda produtiva. Dessa forma, para minimizar esse fator, um estudo sobre a formulação correta que associe uma boa fundência com uma plasticidade correte faz-se necessário [3-5].

Para Morais [6], o controle da granulometria é essencial para alcançar uma boa resistência mecânica das peças.

Para Oliveira [7] na produção de peças cerâmicas procura-se misturar determinadas quantidades de argila de grãos finos com argila de grãos maiores para controlar a plasticidade da massa, a dimensão das peças melhorar 0 índice de plasticidade e a resistência mecânica.

Assim, este trabalho tem por objetivo a determinar as propriedades tecnológicas de cerâmica vermelha queimada $850^{\circ} \mathrm{C}$.

\section{MATERIAIS E MÉTODOS}

Utilizou-se como matéria-prima uma mistura entre argila forte e argila fraca cedida por uma empresa do município de São Miguel do Guamá - PA. A tabela 1 apresenta as massas argilosas estudadas.

Tabela 1. Massas argilosas estudadas

\begin{tabular}{ccc}
\hline $\begin{array}{c}\text { Massas } \\
\text { Estudadas }\end{array}$ & $\begin{array}{c}\text { Argila Forte } \\
(\%)\end{array}$ & $\begin{array}{c}\text { Argila Fraca } \\
(\%)\end{array}$ \\
\hline AFO & 100 & - \\
AFR & - & 100 \\
AFOFR & 50 & 50 \\
\hline
\end{tabular}

As argilas foram secas em estufa de modelo DIMATE, à temperatura de $110^{\circ} \mathrm{C}$ durante $24 \mathrm{~h}$. Após essa etapa o material foi conduzido para o moinho de bolas de modelo Work Index série 005, onde foi realizada a etapa de desagregação, por um período de 30 minutos. Posteriormente seguiu-se para o peneiramento das argilas em peneiras com malha de abertura de 35 mesh para uniformidade dos grãos.

Após essa etapa, separaram-se as formulações estudadas em argila forte, argila fraca e $50 \%$ em peso de argila forte e $50 \%$ em peso de argila fraca. As amostras foram umedecidas com $10 \%$ em peso de água, passadas novamente em moinho de bolas e peneiras e, depois, acondicionadas em sacos plásticos.

Foram confeccionados corpos de prova prismáticos nas dimensões de $10,0 \mathrm{x}$ $5,0 \times 1,0 \mathrm{~cm}$ em matriz metálica. A prensagem uniaxial foi realizada em prensa hidráulica manual Karl Kolb (scientific technical Suplies) aplicando uma carga de 
aproximadamente 8 t. A fabricação dos corpos de prova seguiu as diretrizes da NBR D-6072.

Após a etapa de conformação, os corpos de prova a temperatura ambiente por 24 horas e, depois, em estufa da Ds Diagnóstica a $110^{\circ} \mathrm{C}$ até alcançarem peso constante.

Após a etapa de secagem, os corpos de prova foram medidos com o auxílio de um paquímetro digital da Mitutoyo com precisão de $0,01 \mathrm{~mm}$ e pesado em balança de precisão da Bel com de precisão de 0,001g.

Posteriormente, os corpos de prova foram queimados em forno tipo mufla da EDG, modelo 3P-S na temperatura de 850․ Utilizou-se uma taxa de aquecimento constante de $2^{\circ} \mathrm{C} / \mathrm{min}$ e mantidos na temperatura patamar por 2 horas e resfriados por convecção natural desligando-se o forno.

Após a etapa de queima os corpos de prova foram submetidos ao ensaio de absorção de água de acordo com a norma ASTM C373-72 (ASTM, 1977) [8]. Os corpos de prova foram pesados e posteriormente colocados em um recipiente com água fervente por duas horas e resfriados submersos em água. Posteriormente, foi retirada a água superficial e os corpos de prova foram novamente pesados para que se pudesse obter o valor de absorção de água.

O módulo de ruptura à flexão em 3 pontos foi determinado segundo a norma ASTM C 674-88 [9], sendo considerada a média dos valores de dez corpos-de-prova de cada composição para a temperatura em estudo.

\section{RESULTADOS}

A figura 1 apresenta os valores de absorção de água dos corpos de prova queimados a $850^{\circ} \mathrm{C}$.

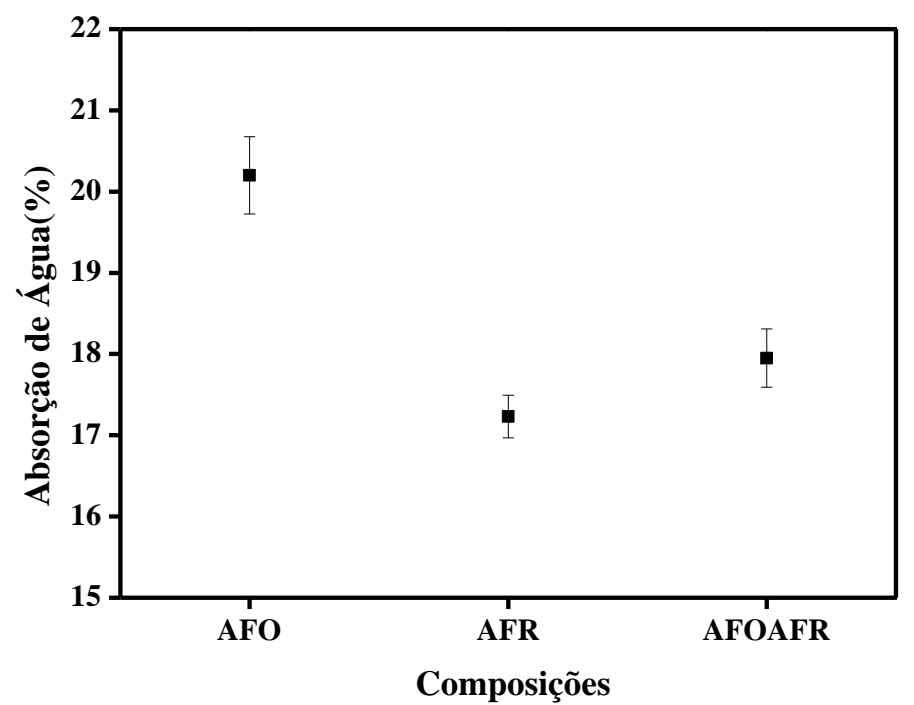

Figura 1. Absorção de água dos corpos de prova queimados a $850^{\circ} \mathrm{C}$.

O maior valor de absorção de água foi observado em corpos de prova confeccionados a partir da argila forte e o menor valor para os confeccionados a partir da argila fraca. Os corpos de prova feitos a partir da mistura da argila forte e da argila fraca apresentaram uma absorção de água média igual a 17,95\%. Apesar da absorção de água da mistura ter sido maior que a da argila fraca, essa composição mássica pode ser uma alternativa para fabricação de peças cerâmicas, 
pois há uma melhoria da plasticidade da massa associada a baixos valores de absorção de água. Todas as composições apresentaram valores para essa propriedade dentro dos requisitos da norma NBR

A figura 2 apresenta o módulo de ruptura em flexão dos corpos de prova queimados a $850^{\circ} \mathrm{C}$.

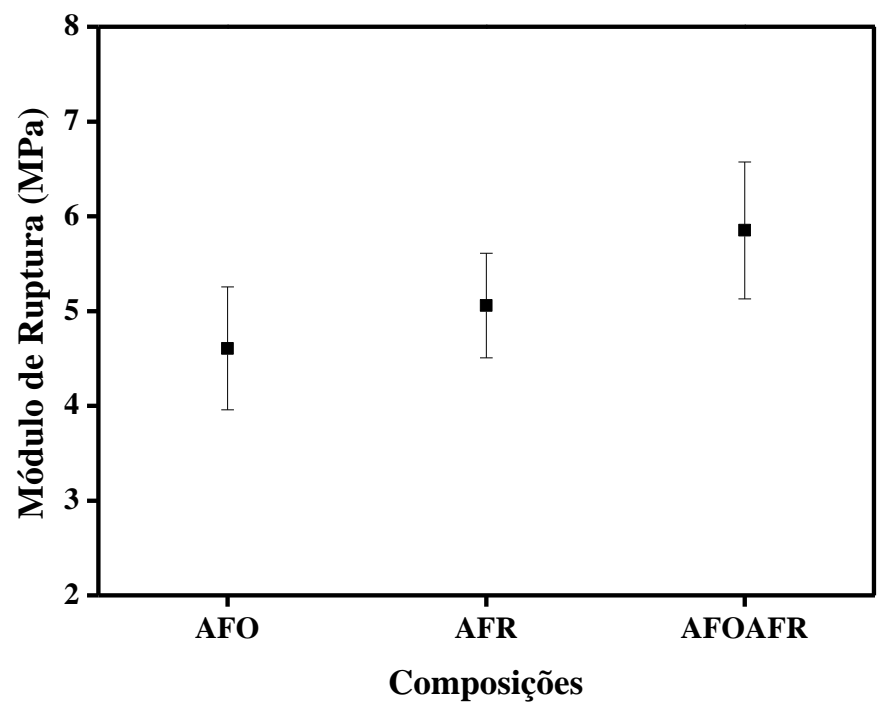

Figura 2. Módulo de ruptura em flexão dos corpos de prova queimados a 850ํ․

Dentro de um erro estatístico, os valores de módulo de ruptura não apresentaram variação significativa, entretanto, ao serem observados os valores médios, nota-se que a composição com $50 \%$ de argila forte e $50 \%$ de argila fraca apresentou melhor desempenho. Esse comportamento pode ser explicado pela melhor trabalhabilidade da massa que influencia diretamente na conformação dos corpos de prova e, consequentemente, no surgimento de microtrincas durante $o$ processo de secagem.

Assim, pode-se inferir que a formulação com a mistura das argilas pode ser uma massa com aplicação industrial, pois apresenta bom desempenho mecânico e valores de absorção de água dentro da faixa recomentada pela NBR 15.270-2 (2005) [10].

\section{CONCLUSÃO}

A determinação das propriedades tecnológicas de cerâmica vermelha queimada a $850^{\circ} \mathrm{C}$ revelou que:

- A composição com $50 \%$ de argila forte e $50 \%$ de argila fraca apresentou a melhor resistência em flexão.

- Os valores de absorção de água e resistência mecânica para todas as composições estão dentro da faixa recomendada por norma.

- A composição AFOAFR pode ser uma formulação empregada na indústria de cerâmica vermelha, pois associa bons valores de resistência mecânica e baixo índice de absorção de água, contribuindo também para o controle dimensional das peças. 


\section{REFERÊNCIAS}

1 Sindicato da Indústria Cerâmica de São Miguel do Guamá e Região - Sindicer. Aglomerados Econômicos De Base Mineral- Experiência Local Sindicer - São Miguel do Guamá, 2012.

2 GV Cordovil. Polo cerâmico e dinâmica territorial do desenvolvimento em São Miguel do Guamá-PA, Belém. Dissertação de mestrado apresentado ao Programa de Pós-graduação em Geografia da Universidade Federal do Pará. 2010.

3 GM Bustamante, JC Bressiani. A indústria cerâmica brasileira. Cerâmica Industrial. 2000; 5(3): 31-36.

4 MA Lima, AS Leite. Características atuais das práticas de cooperação, aprendizagem e inovação no APL Ceramista de São Miguel do Guamá/PA, Desenvolvimento Regional em debate: DRd, 2014; 4(1): 40-62.

5 LG Pedroti, J Alexandre, GC Xavier, SN Monteiro, CMF Vieira, AV Bahiense, PCA Maia. Desenvolvimento de Massa Cerâmica para Blocos Queimados e Prensados. Cerâmica Industrial. 2011; 16 (1): 25-30.

6 DMD Morais, RM Sposto. Propriedades Tecnológicas e Mineralógicas das Argilas e suas Influências na Qualidade de Blocos Cerâmicos de Vedação que Abastecem o Mercado do Distrito Federal. Cerâmica Industrial. 2006; 11(5/6): 35-38.

7 Oliveira, K. R. B. Avaliação dos blocos cerâmicos produzidos para a região metropolitana de Goiânia. 2002. 199 f.. Dissertação (Mestrado) - Universidade Federal de Goiás, Goiânia, GO.

8 American Society for Testing and Materials (1977a). ASTM C373-72. Test method for water absorption, bulk density, apparent porosity and apparent specific gravity of fired whiteware products.

9 American Society for Testing and Materials (1999). ASTM C674-88 Standard Test Methods for Flexural Properties of Ceramic Whiteware Materials.

10 Associação Brasileira de normas Técnicas - ABNT. NBR 15270/2005: componentes cerâmicos. Parte 1: blocos cerâmicos para alvenaria de vedação: terminologia e requisitos. Rio de Janeiro, 2005. 11 p. 